\title{
COMUNIDADES E PLANEJAMENTO URBANO
}

\author{
João Pedro Schmidt ${ }^{1}$ \\ Eliane Fontana ${ }^{2}$
}

\section{Resumo}

Este artigo busca responder à questão: as políticas de planejamento urbano no Brasil, assentadas no considerável arcabouço legislativo pós-Constituição de 1988, vêm incorporando a cooperação pública e o respeito aos vínculos comunitários como variáveis fundamentais? A hipótese que guia o estudo é a de que a política urbana contemporânea brasileira ainda prioriza aspectos econômicos e técnicos - herança da urbanização funcionalista -, com baixa efetividade dos espaços de escuta dos cidadãos, espaços em que a dimensão comunitária das relações sociais pode ser melhor captada pelos agentes públicos. $\mathrm{O}$ artigo utiliza como referencial teórico o comunitarismo, especialmente a teoria comunitarista de Amitai Etzioni, tendo em vista sua ênfase na importância da cooperação entre entes estatais, privados e sociedade civil e na relevância das comunidades para a consecução do bem comum. Os vínculos comunitários são fator de empoderamento dos cidadãos para participar do jogo democrático e do processo de formulação e implementação das políticas, que sempre envolve poderosos interesses. O planejamento urbano, nessa perspectiva, não deve se dobrar à influência unilateral dos interesses econômicos das forças econômicas, particularmente os do setor imobiliário, subjacentes ao viés tecnicista. $\mathrm{O}$ comunitarismo traz também para a seara das políticas públicas a consideração da relevância dos valores, criados e recriados no âmbito das comunidades, enfatizando que os valores da boa sociedade são alicerces da inclusão e a democracia, contrapondo-se aos valores da exclusão e do autoritarismo. $O$ texto elenca exemplos que evidenciam que o modus operandi do planejamento urbano comum no Brasil - a despeito dos mecanismos legais, que incorporam o respeito aos vínculos democráticos e os valores da boa sociedade - não efetiva os preceitos comunitários. A pesquisa é bibliográfico-documental e o método é hipotético-dedutivo.

Palavras-chave: Amitai Etzioni. Comunitarismo. Cooperação pública. Políticas de planejamento urbano.

\section{NOTAS INTRODUTÓRIAS DO TEMA}

Quando há uma desapropriação urbana ou um desalojamento de casas e de bairros por razões econômicas ou ambientais, dentre as várias avaliações (ambientais, sociais e financeiras) exigidas em lei, é comum que a indenização financeira e as condições físicas das novas habitações concentrem as atenções das autoridades e

\footnotetext{
${ }^{1}$ Doutor em Ciência Política pela Universidade Federal do Rio Grande do Sul. Professor titular da Universidade de Santa Cruz do Sul. Docente e pesquisador do Programa de Pós-Graduação em Direito, lotado no Departamento de Ciências Humanas. Coordenador do Grupo de Pesquisa Comunitarismo e Políticas Públicas. E-mail: jpedro@unisc.br

${ }^{2}$ Doutoranda do PPG-Doutorado UNISC. Membro do Grupo de Pesquisa Comunitarismo e Políticas Públicas. E-mail: eliane.fontana859@gmail.com
} 
da opinião pública. A identidade cultural construída por décadas pelos moradores e os elementos imateriais envolvendo o delicado tecido das relações sociais geralmente não são debatidas.

A tragédia de Mariana-MG, no ano de 2015, é um exemplo recente. Face ao caos social e ambiental decorrente do rompimento de uma barragem, o poder público anuncia medidas para alocar os moradores para outros lugares, devendo a empresa responsável pela tragédia arcar com os danos ambientais e as novas moradias. Mas, para os moradores é preciso mais que a reconstrução de suas casas: é preciso reconstruir suas vidas, a rotina dos filhos, a identidade comunitária partilhada com os vizinhos. Dispor dos recursos financeiros para uma nova casa e condições físicas apropriadas para as moradias é fundamental, mas a perda da casa, da rotina e da identidade anterior é algo bem mais complexo.

Os estudos sobre a relevância das questões culturais comunitárias no âmbito das políticas sociais ainda são restritos. Quando da construção do Estatuto da Cidade, em 2001, um interessante debate envolveu autoridades, estudiosos e lideranças da sociedade civil sobre os novos rumos de uma reforma urbana. Desapropriação, preempção, usucapião, Plano Diretor e Audiência Pública tornaram-se expressões difundidas entre o público. Entre os avanços, que vai ao encontro das preocupações deste texto, está a do Estudo do Impacto de Vizinhança, instrumento para prevenir os conflitos de novos empreendimentos com a vizinhança do local. Todavia, não se pode considerar que a lei tenha respondido suficientemente às preocupações com as questões imateriais, simbólicas, culturais, que envolvem uma comunidade. Uma cidade é fruto de múltiplas conexões e interações. Nela está materializada a história de um povo, suas relações sociais, políticas, econômicas e religiosas. Sua existência ao longo do tempo é determinada pela necessidade humana de se agregar, de se inter-relacionar, de se organizar em torno do bem-estar comum; de produzir e trocar bens e serviços; de criar cultura e arte; de manifestar sentimentos e anseios que só se concretizam na diversidade que a vida urbana proporciona.

Em que medida o planejamento urbano no Brasil, a despeito de contar com um considerável arcabouço legislativo pós-Constituição de 1988, vem avançando no reconhecimento da relevância do sentido de comunidade e da cooperação pública (aqui entendida como ação sinérgica entre entres estatais, privados e da sociedade civil)? A hipótese que guia este estudo é a de que a política urbana contemporânea brasileira ainda está muito voltada aos aspectos econômicos e técnicos - herança da urbanização funcionalista -, com baixa efetividade dos espaços de escuta dos cidadãos, espaços em que a dimensão comunitária das relações sociais pode ser melhor captada pelos agentes públicos.

Inicialmente o texto analisa aspectos da política urbana brasileira, atentando para os espaços de debates sobre as percepções, preocupações e anseios dos afetados pelas políticas sociais urbanas. Em seguida, desenvolvese uma reflexão sobre a relevância da cooperação pública na ação de entes estatais, privados e da sociedade civil 
para a consecução de uma política urbana responsiva. Por fim, o artigo explana algumas premissas do comunitarismo responsivo que podem qualificar o debate sobre as políticas urbanas.

\section{PLANEJAMENTO URBANO: PARA QUEM?}

As cidades, segundo Borja e Castells (1996), adquirem cada dia mais proeminência na dinâmica política, econômica, social e cultural das sociedades contemporâneas. Espaços sociais complexos e de múltiplas dimensões, as cidades (incluído o governo local) constituem-se em ator social na medida em que articula administrações públicas, agentes econômicos e privados, organizações sociais e cívicas, intelectuais, profissionais e meios de comunicação social. Para alcançar efetividade, eficácia e eficiência, o planejamento urbano deve levar em conta essa natureza complexa e a diversidade dos agentes envolvidos.

O surgimento do urbanismo e do planejamento urbano deu-se no Brasil no início do século XX (LEME, 1999), associado às demandas da política de saúde coletiva no contexto da chamada era higienista, ${ }^{3}$ que justificavam a destruição das construções decadentes e urbanisticamente desordenadas e favoreciam a disseminação de doenças infectocontagiosas. Os novos espaços construídos a partir dessa ótica "levaram ao encarecimento da terra urbana e ao enobrecimento do território, ${ }^{4}$ resultando na expulsão dos residentes que não pudessem suportar a majoração dos custos fundiários". (SANTOS, 2012, p 3 )

Um dos mais destacados instrumentos de planejamento urbano, implementado no regime militar, foi o Banco Nacional de Habitação (BNH), ${ }^{5}$ instituído em 1964 e extinto em 1986, quando suas funções passaram para a Caixa Econômica Federal. Entre 1964 e 1986, o BNH e o SFH financiaram a construção de 4,3 milhões de casas, sendo 2,4 para o setor popular e 1,9 para o mercado de classe média (BONDUKI, 2008). A partir da década de 1970, o BNH se desviou de sua função original e passou a financiar o desenvolvimento urbano, com ações na área de saneamento urbano (PLANASA).

A legislação, emanada diretamente do Poder Executivo foi então

[...] utilizada na medida de primeiro garantir por parte do Estado o parcelamento, uso e ocupação do solo da maneira que lhe seja mais adequada, e posteriormente, fazendo surgir uma regulamentação urbana que obedeça a critérios rígidos do uso do espaço urbano, a fim de vincular indubitável e irresistivelmente o entendimento ideológico do Estado como

\footnotetext{
${ }^{3}$ Primeiramente, a vertente do urbanismo higienista, influenciando a construção de Belo Horizonte; e posteriormente, a vertente modernista.

${ }^{4}$ Uma das posições críticas é a de Maricato (2000). Para a autora, a invasão de terras urbanas no Brasil é parte intrínseca do processo de urbanização. Ela é gigantesca e não é, fundamentalmente, fruto da ação da esquerda e nem de movimentos sociais que pretendem confrontar a lei. Ela é estrutural e institucionalizada pelo mercado imobiliário excludente e pela ausência de políticas sociais. No entanto, a dimensão e os fatos são dissimulados sob notável ardil ideológico.

${ }^{5}$ Lei no 4.380, de 21 de agosto de 1964. Institui o Sistema Financeiro Habitacional (SFH), o Banco Nacional da Habitação (BNH) e o Serviço Federal de Habitação e Urbanismo (SERFHAU).
} 
criador da cidade-projeto, e a perpetração de interpretação intencionalista e teórica desta sua expressão. (D’ELIA JUNIO, 2011, p. 131)

Santos (2012) explica que tal medida desembocou em fracasso, pois levou ao não-reconhecimento da "cidade ilegal", 6 aquela constituída por parcela crescente da população urbana que não obedece aos parâmetros urbanísticos e jurídicos vigentes. A intensa migração do campo para a cidade nas décadas de 1960 a 1980, uma das mais aceleradas já registradas em nível mundial, que levou o país a ter uma população predominantemente urbana em cerca de três décadas, gerou um notável conjunto de bairros, favelas e conjuntos habitacionais à ma rgem da lei. As tensões envolvendo essa situação habitacional chegaram ao Congresso Constituinte, de no final da década de 1980, expressas por movimentos na defesa de direitos da educação, saúde, reforma agrária, ambiente saudável, água potável, energia elétrica, reforma urbana entre outros. Com relação aos movimentos populares urbanos, lideranças de movimentos sociais, arquitetos, geógrafos, engenheiros elaboraram a Emenda Constitucional e da cidade pela Reforma Urbana. (RODRIGUES, 2007, p. 11). A Carta Constitucional de 1988 incorporou, nos artigos 182 e 183, dispositivos para superar o quadro anterior, marcada por uma legislação urbanística fragmentada, sem sistematização coerente.

O advento de novos instrumentos legais de política urbana, como a Lei Federal no 10.257 de 2001 Estatuto da Cidade, em conjunto com a criação de um ministério específico em 2003 a fim de implementar suas diretrizes - Ministério das Cidades, e as cada vez mais presentes discussões no Legislativo de novos diplomas legais contribuem para um cenário mais receptivo ao compartilhamento das decisões entre Estado e sociedade nas escolhas que afetam a cidade. (D’ELIA JUNIOR, 2011) O Estatuto da Cidade criou diversos mecanismos para assegurar a aplicação da função social da cidade e da propriedade. As audiências públicas tornam-se obrigatórias no âmbito municipal para empreendimentos ou atividades com efeitos potencialmente negativos sobre o meio ambiente natural ou construído, o conforto ou a segurança da população; para a elaboração e fiscalização da implementação do plano diretor; e na gestão orçamentária.

As dificuldades em conciliar diferentes grupos de interesses, associadas às desigualdades da representatividade política, constituem obstáculos sérios para que a ação governamental represente realmente o interesse público. Lefebvre (2008) menciona a cidade "mundial", como uma generalização do fenômeno urbano a qualquer sociedade, um desenvolvimento urbanístico guiado por modas dos tempos modernos, que não tem em

\footnotetext{
${ }^{6}$ Para Borja e Castells (1996, p. 156), quando da realidade latino-americana, o crescimento demográfico, a extensão da cidade "não legal", o peso da marginalidade social, o déficit de infraestrutura moderna e a fraqueza dos governos locais são elementos quantitativos diferenciais.

${ }^{7}$ O Congresso Nacional aprovou, depois de quase onze anos de tramitação, a Lei no 10.257, mais conhecida como Estatuto da Cidade. A Lei, em vigor desde 10 de outubro de 2001, estabelece as diretrizes gerais da política urbana objetivando principalmente o pleno desenvolvimento das funções sociais da cidade e a garantia ao direito a cidades sustentáveis. Sua aprovação é uma conquista dos movimentos populares e da ativa participação de entidades civis em defesa do direito à cidade e à habitação digna.
} 
conta as necessidades específicas da população residente. Para o autor, é uma espécie de efeito totalizador do urbano, guiado por interesses de elites políticas, estatais, que dominam este processo, e onde o cidadão fica excluído na tomada de decisões de um planejamento urbano que afeta a suas formas e estilos de vida, um cidadão relegado ao posto de mero observador (LEFEBVRE, 2008). A crítica do autor é a de que Estado pode induzir a uma privatização em muitos âmbitos da vida social. Assim, Lefebvre (2008) aposta em uma espontaneidade, por uma sociedade civil e pela autogestão. Aqui é indispensável lembrar o conceito de políticas públicas. Embora caiba ao Estado o papel de coordenação das políticas públicas, o "público" não se restringe ao "estatal". A política pública tem sentido "público" quando ultrapassa a vontade política do grupo governante e expressa a vontade do Estado e da sociedade. (SCHMIDT, 2008) A política é primordialmente "polis", comunidade política, que envolve Estado e sociedade civil. A lei deve ser expressão da sinergia Estado-sociedade. Em outras palavras,

a efetivação das normas políticas é indispensável para a formação de sujeitos autônomos, capazes de visualizar no texto constitucional a efetiva possibilidade de seu futuro e não um conjunto afônico de palavras etéreas. A normatividade da norma política aporta segurança no que concerne às políticas públicas, assim como à ética e aos rumos das ações privadas. (DERANI, 2006, p.142)

Políticas públicas não podem ser tratadas como assuntos técnicos, próprios do conhecimento especializado de determinada área, território de experts. É importante que estejam apoiadas em estudos técnicos, mas não se resumem a isso. São sempre, indiferentemente do discurso utilizado, resultado de opções baseadas em valores. Isso se revela com muita nitidez no planejamento urbano, cujos dispositivos e instrumentos carregam pontos de vista e valores. Esses pontos de vista e valores precisam ser discutidos. O plano diretor não deve ser um plano arquitetônico, apartado da cidade vivida, sentida e compartilhada pelos cidadãos. Harvey (2006) destaca que a produção coletiva das cidades envolve ao mesmo tempo a produção coletiva de nós mesmos como sujeitos que pensam e agem nesta sociedade.

O debate sobre o tecnicismo na gestão urbana é ilustrado pelo exemplo do mais polêmico planejador norte-americano, Robert Moses, responsável por retalhar e reconstruir a cidade de New York no início do século passado. Responsável por obras internacionalmente reconhecidas, como o Lincoln Center, o Shea Stadium, a sede da ONU, o traçado das grandes vias que unem a ilha de Manhattan e a cidade e as famosas pontes. Para realizar a reconstrução da cidade, pôs abaixo prédios, casas, ruas, quarteirões históricos e removeu bairros pobres, sem levar em conta a vida das pessoas afetadas por seus projetos. Re-imaginou New York dominada por carros, não por transporte urbano. (DAVILA, 2007)

Uma forte reação à concepção tecnicista de Robert Moses veio de uma moradora da cidade, Jane Jacobs (2000), que se opôs (exitosamente) à tentativa de que seu bairro fosse posto abaixo, mobilizando os cidadãos em torno da ideia de que a cidade não é um conjunto de construções que abrigam pessoas, mas algo vivo, onde as 
relações entre as pessoas são o elemento fundamental. Autodidata, sistematizou suas ideias no conhecido livro "Morte e Vida de Grandes Cidades", publicado em 1961, que impactou profundamente o pensamento urbanista. Jacobs chamou a atenção para a importância do desenho dos bairros, das ruas e das calçadas na intensidade e qualidade da vida social. A Autora defendeu a dinâmica das ruas das metrópoles, com alta densidade de transeuntes e sempre cheias de desconhecidos, argumentando que a sensação de segurança das pessoas diante dos desconhecidos depende essencialmente da intensa circulação e dos múltiplos olhares. Quanto mais olhares uma rua recebe, mais segura será; bairros considerados tranquilos podem se tornar perigosos na ausência desses olhares. A vida pública informal e as redes entre os moradores são vitais para a vida dos bairros. Essas redes constituem o "capital social urbano insubstituível", afirmou Jacobs, num uso pioneiro da expressão "capital social", apontando a importância dos cidadãos como sujeitos ativos do seu espaço social. Santos (2012, p. 8) reconhece a enorme contribuição de Jacobs para a reformulação da concepção do planejamento urbano, rompendo com a visão de atividade técnica e introduzindo a necessidade da participação popular.

Alguns exemplos sobre valores a serem discutidos em questões aparentemente técnicas: nas vias urbanas, as regras asseguram preferência para os carros ou para o transporte coletivo e a bicicleta? No caso da segurança, maior conforto para fazer compras ou para andar com segurança a pé? O presídio e a casa de recuperação de jovens infratores devem ficar em área central, na periferia rica, na periferia pobre ou fora da cidade? É aceitável que o poder público aceite trocar área construída pelas construtoras nos centros urbanos em troca de preservação ambiental fora da cidade? A decisão sobre os valores implícitos em decisões aparentemente técnicas é da alçada tanto dos gestores como dos cidadãos.

Para Santos (1992, p. 241), a "cidade" difere do "urbano". A cidade "é o concreto, o conjunto de redes, enfim a materialidade visível do urbano, enquanto que este é o abstrato, porém o que dá sentido e natureza à cidade". O que se pode inferir a partir disso, é que cidade e urbano se interpenetram, estão amalgamados, e só aparentemente o Estado está acima das contradições e conflitos que produzem e reproduzem a desigualdade socioespacial. (RODRIGUES, 2007). Os problemas advindos da urbanização, como a segregação espacial, são frequentemente causados pela tentativa de impor um modelo de urbanização baseado numa cidade ideal a uma cidade real, a qual é distinta nos seus fundamentos daquela cidade idealizada. A segregação é um "processo segundo o qual diferentes classes ou camadas sociais tendem a se concentrar cada vez mais em diferentes regiões gerais ou conjuntos de bairros da metrópole" (VILLAÇA, 2001, p. 142). Com o deslocamento progressivo dos serviços e equipamentos urbanos na direção das áreas de mais alta renda, a localização das outras classes vai se tornando progressivamente (relativamente) pior. Assim, inicialmente a localização das elites tende a ser uma área próxima ao centro (SABOYA, 2009). 
Santos aponta os desafios atuais do planejamento urbano à luz de duas agendas políticas distintas:

A primeira delas é a agenda do empreendedorismo urbano, que inclui: planejamento estratégico; operações consorciadas; parcerias público-privadas para financiamento de investimentos, dentre outras iniciativas, todas consideradas a partir da ótica do mercado. Mas há também uma outra agenda, a do ativismo democrático, que inclui o plano diretor, a criação de conselhos populares (para controle das políticas de saúde, educação e assistência social, por exemplo), o orçamento participativo, além da defesa do meio ambiente. Essa é a agenda que envolve participação popular e que vai ao encontro das reformas do Estado orientadas para o public service orientation, segundo a qual cabe ao poder público desenvolver políticas com mais transparência em seu processo e que resultem em responsabilização do gestor público (SANTOS, 2012, p. 25, grifos nossos)

De um lado, a participação em si mesma ocorre num espaço crescentemente politizado, onde a disputa pelo Estado e pela hegemonia é permanente, ao mesmo tempo em que se exerce o esforço da concertação e da construção da mediação e da composição dos interesses sociais, autonomizados e mesmo antagonizados. De outro lado, a ampliação das demandas em prol de maior equidade e igualdade pressupõe uma ampliação da capacidade de intervenção do Estado, seja no que diz respeito ao planejamento, à coordenação, à gestão ou à implementação de políticas públicas (SILVA; JACCOUD; BEGHIN, 2005, p. 378), seja quanto à sua capacidade de interferir nos conflitos sociais.

\section{COMUNIDADES E COOPERAÇÃO PÚBLICA NO PLANEJAMENTO URBANO RESPONSIVO}

Aplicam-se às políticas públicas do planejamento urbano requerimentos que valem para as políticas em geral, entre elas as que se referem à sinergia da ação governamental com as comunidades e as redes de cidadãos. A conceituação jurídico-formal de Bucci (2006, p. 47) contempla essa exigência ao estabelecer que políticas públicas e se justifica do ponto de vista da funcionalidade do direito, isto é, das condições de atuação de vários agentes, públicos e privados, envolvidos na concretização dos direitos sociais e, mais que isso, em toda a gama de intervenções do Estado sobre o âmbito privado. Para a autora, as políticas públicas "atuam de forma complementar, preenchendo os espaços normativos e concretizando os princípios e regras, com vista a objetivos determinados" (2006, p. 26).

O pensamento comunitarista reforça a relevância da sinergia dos entes públicos, sociais e privados para o êxito das políticas. O comunitarismo contemporâneo representa o retorno do conceito de "comunidade" ao debate público, não de uma forma saudosista, associada às comunidades agrárias pré-modernas, ou num sentido utópico de uma vida sem conflitos. Os comunitaristas constatam que mesmo nas sociedades urbanizadas dos tempos atuais as comunidades continuam sendo uma realidade da vida social. As pessoas "naturalmente" formam redes de afinidades, compartilhando ideias, valores e afetos, que em grande parte orientam o comportamento 
individual. É inviável, para os comunitaristas, tentar entender a dinâmica social e o comportamento das pessoas sem levar em conta as comunidades em que vivem. E, por isso, é inviável entender a política sem levar em conta as comunidades e sua relação com o poder público. (SCHMIDT, 2015)

A reflexão comunitarista anglo-saxã enfatiza fortemente a importância dos valores na política e nas políticas públicas, valores criados, recriados e disseminados pelas comunidades. A democracia só se enraíza na vida social quando os valores comunitários legitimam a democracia. Um estilo político de gestão horizontalizada (e não hierárquica), desde a formação da agenda até a avaliação de uma política pública, é compatível com comunidades democratizadas. Isso significa que a responsabilidade é dividida entre o Estado, a comunidade (sociedade civil, terceiro setor) e o setor privado.

O conceito de cooperação pública, desenvolvido por Jonathan Boswell (1994), traduz bem a concepção comunitarista e tem plena aplicabilidade no âmbito das políticas urbanas. Mesmo levando em conta que frequentemente agentes públicos, agentes privados e comunidades particulares expressam pontos de vistas particulares e que se opõe mutuamente, Boswell entende que é possível um movimento sinérgico desses agentes em prol do interesse público, como se verificou em diversos momentos históricos de convergência entre governos, empresas, sindicatos e organizações sociais. A cooperação pública é fundamental na definição dos rumos das cidades. $\mathrm{O}$ esforço dos agentes do Estado, do mercado e comunidade complementam-se, a fim de buscarem as melhores soluções do ponto de vista social, político e ambiental. A existência de múltiplos interesses nas disputas espaciais urbanas é próprio da vida social, um processo complexo e de permanentes tensões. Mas, é próprio da política o esforço em superar os antagonismos e buscar convergências.

Cooperação pública é uma forma de assegurar responsividade das instituições políticas e ao mercado. "Ser responsivo" é a capacidade de "dar resposta" aos anseios das pessoas, um item essencial para assegurar a legitimidade do poder público e das instituições em geral. (ETZIONI, 2000) As grandes estruturas da modernidade trouxeram enorme risco dos cidadãos se reconhecerem cada vez menos no Estado, nas corporações privadas e nas instituições. A alienação, descrita por Marx, é uma sombra que recobre grande parte da ação estatal e do mercado, incluindo-se aí o planejamento urbano.

Osborne e Gaebler (1994) relatam um conjunto de inovações no modo de funcionamento das esferas federal, estadual e local do governo norte-americano nas últimas décadas e mencionam uma série de casos em que o espírito sinérgico transformou o setor público, representando uma verdadeira reinvenção do governo. Essa reinvenção é fruto de uma expectativa dos cidadãos:

Os norte-americanos têm o desejo de exercer maior controle sobre os assuntos que afetam diretamente a sua vida: a segurança pública, as escolas dos seus filhos, os construtores que querem transformar o ambiente onde vivem. Esses são assuntos pelos quais há tanto 
interesse que muitos de nós dedicamos horas preciosas, a cada semana, ao trabalho voluntário nas escolas, às vigílias comunitárias ou às organizações de vizinhança. É, precisamente nesse ponto, que a participação democrática está se tornando real dentro dos governos desse país (OSBORNE; GAEBLER, 1994, p. 78).

As ações de complementaridade e de convergência de responsabilidades do campo político são também comuns no Brasil e em muitos países. As agências internacionais vêm estudando experiências de participação nos diferentes continentes e recomendam fortemente que os agentes governamentais compartilhem o controle das ações e das escolhas públicas com as comunidades e envolvam suas organizações na execução de serviços públicos. É dessa essência - cooperativa - que se estabelece a premissa de uma construção - tripartida - de responsabilidade no planejamento urbano proposto aqui.

Cooperação pública é um conceito sociológico-político, não utilizado (ainda) no instrumental jurídico brasileiro, mas que está em perfeita sintonia com conceito de cooperação inscrito da Constituição Federal e com diversas leis infraconstitucionais, a exemplo do Estatuto da Cidade. Cooperação pública em vista do "interesse público" e do "bem comum". Interesse público e bem comum que só podem ser alcançados no debate aberto na esfera pública, onde os interesses e as expectativas se tornam transparentes, viabilizando diálogos morais (de convicções) sobre o que é melhor para o conjunto da sociedade.

Pensar o planejamento territorial nos níveis municipal, microrregional e mesorregional envolve dar sentido comum aos diferentes entendimentos de representantes de comunidades particulares de regiões, municípios, distritos, localidades. Para este fim, deve-se criar espaços para o exercício da democracia direta, na forma de foros de desenvolvimento local de forma a empoderar as comunidades para que elas assumam um papel ativo e criativo no desenho do seu futuro. (SACHS, 2008, p. 61)

A cidade é mais que um conjunto de ruas e construções habitadas por pessoas. A cidade é também um espaço simbiótico (poder político-sociedade civil) e simbólico (que integra
culturalmente, dá identidade coletiva a seus habitantes e tem um valor de marca e de
dinâmica com relação ao exterior), converte-se num âmbito de respostas possíveis aos
propósitos econômicos, políticos e culturais de nossa época. Citemos três. A necessidade de
dar respostas integradas e não setoriais aos problemas de emprego, educação, cultura,
moradia, transportes etc.; o estabelecimento de compromissos públicos e privados a partir
das demandas do crescimento econômico e do meio ambiente; a configuração de novos
espaços e mecanismos que estimulem a participação política (BORJA; CASTELLS, 1996, p.
157, grifos nossos) Mas, como fazer? Para Sachs (2008), o planejamento é um processo interativo que inclui procedimentos de baixo para cima e de cima para baixo dentro do marco de um projeto nacional de longo prazo, uma visão compartilhada pela maioria dos cidadãos da nação sobre valores, a sua conversão em objetivos societais e a inserção do seu Estado-Nação num mundo globalizado. Uma perceptiva sinérgica entre as esferas na elaboração de um projeto de cidade e, portanto, de um planejamento urbano não-técnico, mais responsivo às necessidades da 
comunidade local, demanda pensar num governo local capaz de comprometer-se na criação de espaços de debate público- o que remonta à ideia de capilaridade; e, na ideia de pertencimento, o que permite estabelecer uma relação direta e imediata da organização e na efetiva cooperação Inter-administrativa.

O âmbito local (bairro, cidade, região) é um marco adequado na experimentação e desenvolvimento, de descentralização territorial e funcional, de participação na gestão e execução de programas públicos. A democracia renovar-se-á a partir do princípio de proximidade, complemento indispensável das construções políticas supranacionais atualmente em curso. A cooperação pública implica em interação, sinergia, compartilhamento de responsabilidades, não em competências e funções dos governos locais puramente definidas em uma legislação estatal uniformizadora, sem outros critérios, tais como proximidade, capacidade, associação, demanda social e diversidade. (BORJA; CASTELLS, 1996, p. 160-161)

Uma experiência interessante, relatada por Grau-Sóles, Rueda e Subirats (2012), é a controvérsia em torno do processo de transformação urbana do bairro Casc Antic, em Barcelona. A revitalização de uma das praças do bairro tinha visava atender expectativas como construção de hortas urbanas, instalação de equipamentos de playground, lojas, banheiros públicos e chuveiros, espaço para basquete, a possibilidade de ruído durante a noite, o uso da praça pela população migrante, etc. Todos esses elementos em jogo compunham um cenário de diversidade, que foram organizados em diferentes versões de enquadramento. O principal problema é que muitos dos elementos contidos nas decisões sobre o (re)desenho da praça não perpassavam o processo de participação das escolhas. A participação dos cidadãos nas grandes intervenções urbanas do bairro Casc Antic foi "enquadrada" no viés jurídico, de natureza estritamente técnica, e, acima de tudo, dos aspectos arquitetônicos.

En la práctica, no obstante, como hemos visto en los casos estudiados, las entidades del barrio quieren participar tanto sobre la filosofía del espacio, como en los usos, el diseño, los materiales, la gestión, etc.

Aquí las dicotomías de la modernidad son menos presentes. No "saben" distinguir entre lo que es social y "participable" y el que es técnico y objetivo.Transgreden la división. (GRAUSÓLES; ROEDA; SUBIRATS, 2012, p. 101)

Impossível não questionar: quem faz a cidade? Arantes (2000), em uma obra crítica sobre gestões urbanas, responde que, ao menos a partir dos anos 1990, inequivocamente são as grandes empresas, com as mediações de praxe. A autora propõe que uma combinação de "cultura cívica" e "consenso público" ou, ainda na mesma linha do eufemismo, "vontade conjunta", formariam a argamassa dessa construção de cidade, permitindoThe dar "um salto adiante, tanto do ponto de vista físico como econômico, social e cultural" (ARANTES, 2000, p. 57). Um contraponto a essa tendência estaria também em Barcelona: com vistas às Olimpíadas de 1992, no final dos anos 1980, a cidade adotou um projeto de remodelamento urbano da cidade que, embora propusesse uma vitrine auspiciosa para a cultura local, foi engendrada por americanos (nem os projetistas eram ibéricos). Mas, o processo adotado no remodelamento permitiu a mistura de regionalismos e ultramodernismos e resultou, ao final, 
em uma fórmula hibrida, com o incremento valioso da opinião pública:

[...] a "marca" Barcelona: trata-se - dizia ele - de "uma articulação entre atores públicos e privados para promover estratégias concertadas de desenvolvimento e sua organização para uma ação conjunta". O que significa uma ampla participação das instituições e mesmo da população, partindo - acreditava o presidente do Conselho - "de diálogo sincero e de vontade de consenso" (I) Ora, o empenho dos indivíduos, ao que parece promovidos ao grau de cidadãos, teria como poder catalisador a afirmação da identidade político-cultural - e assim por diante, de ambiguidade a mal-entendido entre política real e epiderme cultural. (ARANTES, 2000, p. 56)

Nota-se nos casos espanhóis relatados que a identidade comunitária está em jogo nas escolhas que orientam o planejamento e só se manifesta quando há espaços para debates-diálogos comunitários. No Brasil, Maricato (2000, p. 179) aponta uma série de condições para o enfrentamento de disputas urbanas e fragmentação-segregação e desigualdade na distribuição dos espaços, tais como: a criação de um espaço de debate democrático com participação ativa dos excluídos e reconhecimento dos conflitos; a elaboração de um Plano de Ação ao invés de Plano Diretor, com destaque para as diretrizes quanto ao controle e orientação dos investimentos, fiscalização do uso e da ocupação do solo, enfoque integrado das ações sociais, ambientais e econômicas, detalhamento de planos executivos, específicos, das prioridades: habitação, transportes públicos e meio ambiente além de menções à infraestrutura de informação sobre as cidades e formação de quadros para a gestão urbana para todos os cidadãos. $\mathrm{O}$ ponto fundamental toca exatamente na crítica às agendas dominantes das reformas urbanas: a ausência de esclarecimentos e debate com a comunidade sobre as obras, as modificações vicinais que geram impacto na segurança, na saúde e na rotina de quem vive naquele espaço.

Romper com os particularismos em favor de uma visão integradora é um dos desafios centrais da política. Etzioni (1999, p. 225) recorre ao conceito de comunidade de comunidades e diversidade na unidade para reforçar a importância da construção de relações entre as comunidades, pois do contrário se está diante de "ilhas comunitárias em um oceano não comunitário". O desafio é construir vias entre os laços individuais e locais com a comunidade mais extensa, priorizando o bem comum. Na relação das comunidades locais e da cidade ampla, o poder público deve atentar para o risco de comunidades economicamente mais poderosas sobreporem seus interesses aos das comunidades mais pobres, como no caso da localização de equipamentos públicos desejados (praças públicas, parques e universidades são bem-vindos em bairros ricos) ou indesejados (presídios geralmente são construídos em bairros pobres ou distantes de áreas centrais). Requer-se que o poder público zele pelo interesse conjunto da cidade, o que significa frequentemente opor-se aos grupos mais organizados e ruidosos.

Esses laços, segundo Etzioni, não podem ser construídos com base em uma estratégia deliberativa de tipo racional, como pensa Habermas. Os laços mais amplos só se sustentam se estiverem assentados num núcleo de valores comuns. Os códigos morais não são fruto de consenso racional, são fruto de um diálogo sobre as 
conviç̧ões profundas, sobre os valores fundamentais de cada comunidade. É mais que razão, é sentimento, valoração. (ETZIONI, 1999, p. 253). O núcleo valorativo das comunidades deve ser contemplado nas políticas públicas para que tenham legitimidade, a qual cria condições para a eficácia e eficiência.

\section{PREMISSAS COMUNITARISTAS PARA O PLANEJAMENTO URBANO}

Ao encontro das preocupações com a legitimidade e da inclusão das comunidades nas políticas, estudo do IPEA (2011) traz sugestões quanto à integração do território e ao senso de pertencimento à cidade. São necessários dois tipos de ação. Um, a integração dos fragmentos ou zonas da cidade e de seus tempos, ou seja, do trabalho, do lazer, do morar. Essa é a integração que supera a visão funcionalista da cidade. Outro é o das ações para se produzir urbanidade, integração da cidade, minimização das desigualdades socioespaciais, com ampliação do acesso à terra, o cumprimento da função social, superando fronteiras físicas e simbólicas e racionalizando o uso da infraestrutura. Essas condições avalizam uma política de Estado, uma proposta de urbanismo, de sociedade. Como o Instituto expõe,

o poder público, por meio da cooperação federativa e da integração de ações tem responsabilidades, verticais e horizontais. A sociedade civil, que com participação, controle e responsabilidade social deve impor não apenas suas necessidades imediatas, mas as formas de assegurar que as cidades sejam espaços de integração. E o capital privado, que deve assumir seu papel edificante nesta empreitada, rumo a uma cidade mais dinâmica, racional e acessível (IPEA, texto digital, 2011, grifos nossos).

Nota-se, acima, que deve haver ação conjunta, cada qual com papeis bem definidos, todos fundamentais à consecução da política. A cooperação entre o poder estatal, a comunidade e o mercado é a fórmula mais segura de manter o equilíbrio nas escolhas, nas decisões e do plano de ação. Algumas premissas comunitárias, se estivessem mais presentes na cultura político-jurídica do país poderiam melhor responder aos anseios da sociedade. Evidenciar a comunidade proporciona um ângulo de abordagem especialmente propício ao tema do espaço local. A leitura comunitarista da vida social recepciona a ideia de subsidiariedade, enaltecendo o papel da família e das organizações locais na solução de problemas e prestação de serviços de interesse coletivo. Etzioni assinala que as comunidades podem desempenhar um papel relevante no âmbito das políticas sociais, com maior qualidade humana que o Estado. Sua importância é tamanha que "as comunidades podem chegar a ser a mais importante nova fonte de serviços sociais no futuro previsível” (ETZIONI, 2001, p. 30). O destaque ao espaço local não representa de modo algum a desvalorização das instâncias de poder nacional e internacional, e sim um viés que destaca a necessária articulação das questões locais à dinâmica do Estado Nacional e do processo de globalização.

Essa linha de preocupação tem especial relevância nos dias atuais. Dois casos servem para ilustrá-la. Na 
tarde do dia 5 de novembro de 2015, o rompimento da Barragem do Fundão, localizada na cidade histórica de Mariana (MG), foi responsável pelo lançamento no meio ambiente de 34 milhões de $\mathrm{m}^{3}$ de lama, resultantes da produção de minério de ferro pela mineradora Samarco - empresa controlada pela Vale e pela britânica BHP Billiton. É um dos maiores desastres ambientais da história do Brasil e deixou pelo menos 11 mortos, 12 desaparecidos e mais de 600 desabrigados. Os milhões de metros cúbicos de lama despejados percorrem um trajeto de mais de 500 quilômetros que atingiu o estado do Espírito Santo. Milhares de notícias estão relacionadas a este evento desastroso e de proporções inimagináveis, e quase todas relacionadas com o impacto econômico e ambiental. Não se pode olvidar, todavia, os impactos sociais e políticos correlacionados. Há uma comunidade que perdeu pessoas e bens, há pessoas cujos vínculos sociais foram modificados para sempre, cuja vida nunca mais será a mesma. Depoimentos nos meios de comunicações mostram que os moradores não querem apenas uma casa melhor, receber indenização para adquirir uma nova casa, mas, queixam-se de não serem ouvidos sobre suas preocupações com a reconstrução do povoado, de ter os mesmos vizinhos, aquilo que realmente importa na reconstrução de suas vidas.

As mesmas preocupações apareceram no processo de urbanização da Vila Chocolatão, em Porto Alegre, no ano de 2011. Os documentos (NEVES, 2011; STROHAECKER, 2011) relatam que, após vinte e cinco anos da existência da Vila Chocolatão (chamada assim por ter crescido no entorno de prédios público no centro da cidade, especialmente ao lado do prédio marrom-espelhado da Receita Federal) uma ação de Reintegração de Posse intentada pela União sobre a propriedade onde se localizava a Vila, desembocou no realocação de 732 pessoas (181 famílias e 225 unidades habitacionais (NEVES, 2011, p. 19) para outro local da cidade de Porto Alegre. A "Nova Vila Chocolatão" foi projetada com casas uniformemente edificadas, de alvenaria e dois quartos, para abrigar os moradores da Antiga Vila no centro da cidade. Por ocasião dos despejos judiciais dos moradores, todo o processo de realocação, destruição da vila e ouvida dos moradores foi documentado e acompanhado, inclusive, por representantes da ONU, da Secretaria local de habitação e de demais órgãos com o intuito de garantir que houvesse transparência e proteção no deslocamento das famílias. Observa-se que a quase totalidade dos moradores vivem da reciclagem do lixo, são em sua maioria semianalfabetos (muito embora grade parte das crianças frequentavam a escola pela localização central da Vila).

Todavia, ao contrário do que a mídia frequentemente relatou - de que se tratava de uma "chaga aberta na cidade" - (NEVES, 2011), levando a identidade da Vila Chocolatão a uma patologia ou mesmo uma vergonha para a cidade em vias de receber a Copa de 2014 (NEVES, 2011), cada família que ali vivia compunha uma identidade que se harmonizava ao trabalho e a rotina da comunidade da Chocolatão e tal premissa foi totalmente ignorada quando do processo de desalojamento. A Vila tinha identidade, e seus moradores não queriam 
"melhores casas", mas queriam os mesmos vizinhos. Assim, muitos passaram a fazer "puxadinhos" porque tinham o costume de sentar sob as áreas das casas e isso era uma identidade daquela localidade, elementos comunitários e valorativos que não compunham o cenário que passaram a morar. O número de moradores em cada casa também foi desconsiderado vez que a nova Vila é composta de casas com somente dois dormitórios.

Esses dois exemplos ilustram a compreensão dos comunitaristas acerca do que significado de comunidade: compartilhamento de valores e de vínculos de afeto. A cultura moral é um processo longo, não pode ser imposto e nem é fruto de consensos racionais. Sob os interesses, os argumentos racionais e arranjos procedimentais há uma "camada mais profunda" de valores, emoções, sentimentos. Os valores compartidos são aqueles com os quais a maioria dos membros da comunidade tem um compromisso de vida, que organizam a visão de mundo e o seu comportamento. Esse núcleo valorativo deve ser levado em conta pelo Estado quando da formulação e implementação de políticas públicas.

Os diálogos morais (diálogos sobre valores) estão na raiz das transformações da cultura moral. São conversações sobre convicções, que transcorrem no dia a dia, não entre experts, mas entre cidadãos, no ambiente do lar, das amizades, do trabalho, das comunidades. Mesmo que a discussão pareça desorganizada e divagante, é através desse processo que as pessoas modificam suas crenças, condutas e sentimentos. (ETZIONI, 2000, p. 6465). Conectar os debates públicos aos diálogos morais cotidianos é um requisito da boa política e da cooperação pública.

A ênfase nos valores comunitários requer que o poder local seja pensado em íntima relação com as tradições, os costumes e as formas de vida próprias de cada ambiente. Decisões dos agentes públicos ou debates que desconhecem os valores da comunidade local, aparentemente desapaixonados e nos quais os agentes estatais apresentam suas posições com linguagem tecnicista jamais serão capazes de impulsionar a construção de uma boa sociedade, caracterizada por relações dialógicas e pela participação ativa dos cidadãos na esfera pública.

\section{NOTAS CONCLUSIVAS}

A fragmentação social, uma característica especialmente forte nas grandes cidades, é um dos obstáculos para a tomada de decisões coletivas com aceitação ampla. O planejamento urbano é particularmente sensível à ausência de redes e conexões sociais robustas, o que vem levando a políticas de urbanização pensadas de forma tecnicista e unilateral. Quando o planejamento urbano está desconectado da rotina e da vivência dos moradores da cidade sua legitimidade é baixa, o que incide severamente na eficiência e eficácia dos seus mecanismos e dispositivos. A ênfase tecnicista na consecução do Plano Diretor vem levando a cidades não inclusivas, espacial e socialmente desiguais, corroborando a fragmentação cultural e econômica da cena urbana contemporânea. 
O pensamento comunitarista alerta para a atenção que o gestor público deve ter quanto à importância das comunidades, que continuam existindo, sob diferentes formas, inclusive nos centros urbanos, seja na forma de organizações formais ou de redes informais. As premissas comunitaristas realçam a cooperação entre Estado, comunidade e mercado na construção de uma política urbana que responda aos anseios da sociedade. Social, porque o comunitarismo enaltece o indivíduo como um ser social em sua essência, que jamais pode ser pensado desagregado do convívio do grupo; político, porque o comunitarismo enaltece a comunidade fortalecida e envolvida de maneira que ela mesma se empodere e eleja seus valores, dá azo à construção de políticas comunitárias específicas; por fim, econômico, pois a chave da abordagem comunitária para a economia é a busca de equilíbrio entre a livre iniciativa e o bem social. A leitura comunitarista da vida social recepciona a ideia de subsidiariedade, enaltecendo o papel da família e das organizações locais na solução de problemas e prestação de serviços de interesse coletivo, o que contribui para o planejamento urbano sinergicamente construído, tendo em vista as múltiplas interações sociais que a cidade comporta.

No planejamento urbano, o que falta para a atuação sinérgica entre entes estatais, privados e comunidade não são mecanismos legais. O que falta é a incorporação da premissa de que a comunidade, os laços comunitários realmente fazem diferença.

\title{
COMMUNITIES AND URBAN PLANNING
}

\begin{abstract}
The present study aims to answer the question: urban planning policies in Brazil, settled in considerable postlegislative framework from the Constitution of 1988 are incorporating public cooperation and respect for communitarian ties as key variables? The hypothesis that guides the study is that Brazilian contemporary urban policy also gives priority to economic and technical aspects -inheritance of the functionalist urbanization - with low effectiveness of listening spaces of citizens, spaces where the communitarian dimension of social relations can be better captured by government agents. The study uses as a theoretical background the communitarianism, especially the communitarian theory from Amitai Etzioni, given its emphasis on the importance of cooperation between state bodies, private and civil society and the importance of communities to achieve the common good. Communitarian links are empowerment factor of citizens to participate in the democratic process and the formulation and implementation of policies, which always involves powerful interests. Urban planning, in this view, must not bend to the unilateral influence of the economic interests of the economic forces, particularly the real estate sector, underlying the technicalities/ technicist bias. Communitarianism also brings to focus of public policy the consideration of the relevance of values, created and re-created within communities, emphasizing that the values of good society, which are foundations of inclusion and democracy, in contrast to the values of exclusion and authoritarianism. The text lists examples that show that the modus operandi of the common urban planning in Brazil - despite the legal mechanisms that incorporate respect for democratic ties and the values of good society - ineffective communitarian precepts. The research is bibliographical and documentary and the method is hypothetical-deductive.
\end{abstract}


Keyworks: Amitai Etzioni. Communitarianism. Public cooperation. Urban planning policies

\section{REFERENCIAS}

ARANTES, Otilia B. Uma estratégia fatal: a cultura nas novas gestões urbanas. In: ARANTES; Otília; VAINER, Carlos; MARICATO, Ermínia. A cidade do pensamento único: desmanchando consensos. Petrópolis: Vozes, 2000.

BRASIL. Estatuto da cidade: guia para implementação pelos municípios e cidadãos: Lei n. 10.257, de 10 de julho de 2001, que estabelece diretrizes gerais da política urbana. 2. ed. Brasília: Câmara dos Deputados, Coordenação de Publicações, 2002.

BONDUKI, N. G. (2008). Política habitacional e inclusão social no Brasil: revisão histórica e novas perspectivas no governo Lula. Revista Arquitetura e Urbanismo, São Paulo, Universidade São Judas Tadeu.

BOSWELL, Jonathan. Community and the economy: the theory of public co-operation. New York: Routlege, 1994.

BUCCI, Maria Paula. O conceito de política pública em direito. In: BUCCI, Maria Paula Dallari. (org.) Políticas públicas: reflexões sobre o conceito jurídico. São Paulo: Saraiva, 2006, p. 01-50.

CASTELLS, Manuel; BORJA, Jordi. Trad. Omar Ribeiro Thomaz. As cidades como atores políticos. Revista Novos Estudos CEBRAP n. 45, julho 1996, pp. 152-166.

DÁVILA, Sérgio. Morar Mundo: o homem que retalhou NY. Folha Online, 30/03/2007. Disponível em http://www1.folha.uol.com.br/folha/especial/2007/morar2/rf3003200701.shtml. Acesso em 02/05/2016.

D’ELIA JUNIOR, Antônio. Morada do poder: a experiência republicana das capitais planejadas. In: Revista de Direito da Cidade, v. $\quad 3, \quad$ n. 1. Disponível em: www.epublicacoes.uerj.br/index.php/rdc/article/download/9928/7767. Acesso em 02/04/ 2016.

DERANI, Cristiane. Política pública e norma política. In BUCCI, Maria Paula Dallari. Políticas públicas: reflexões sobre o conceito jurídico. São Paulo: Saraiva. 2006.

ETZIONI, Amitai. La nueva regla de oro: comunidad y moralidad en una sociedad democrática. Barcelona: Paidos, 1999.

La tercera via hacia uma buena sociedad: propuestas desde El comunitarismo. Sagasta: Trotta,S. A. 2000.

FONT, Joan (coord.). Ciudadanos y decisiones públicas. Barcelona: Ariel, 2007;

GRAU-SOLÉS, Marc; ÍNIIGUEZ-RUEDA, Lupicinio; SUBIRATS. Una perspectiva híbrida y no-moderna para los estudios urbanos. Athenea Digital, v. 12, n. 1, p. 89-108, março 2012.

HARVEY, David. Espaço de esperança. São Paulo: Loyola, 2004 
IPEA - INSTITUTO DE PESQUISA SOCIAL E APLICADA. Política Urbana e Integração Territorial, 201 1, ano 8,64 edição 64 Disponível http: $/ /$ www.ipea.gov.br/desafios/index.php?option=com_content\&view=article\&id=2353: catid=28\&Itemid=2 3. Acesso em 05/04/2016.

JACOBS, Jane. Morte e vida de grandes cidades. Sa o Paulo, Martins Fontes, 2000.

LEME, M. C. (org.) Urbanismo no Brasil de 1895-1965. São Paulo: Studio Nobel, 1999.

LEFEBVRE, Henri. A revolução urbana. 3. imp. Belo Horizonte: UFMG, 2008.

MARICATO, Ermínia. A cidade do pensamento único: desmanchando consensos. Petrópolis: Vozes, 2000.

NEVES, Marcos F. A estética do acaso: um estudo antropológico sobre a dinâmica estética e econômica na Vila Chocolatão. Universidade Federal do Rio Grande do Sul, 2011. Trabalho de Conclusão de Curso. Disponível em: http://biblioteca.versila.com/2441492. Acesso em 12/05/2016.

RODRIGUES, Arlete Moysés. Desigualdades socioespaciais - a luta pelo direito à cidade. Revista Cidades, v. 4, n. 6, 2007, p. 73-88.

SABOYA, Renato. Segregação espacial urbana. Urbanidades: Urbanismo, Planejamento Urbano e Planos Diretores. Homepage Disponível em : http://urbanidades.arq.br/. Acesso em 01 de agosto de 2016.

SACHS, Ignacy. Desenvolvimento: includente, sustentável, sustentado. Rio de Janeiro: Garamond, 2008.

SANTOS, Ângela M. S. P. Planejamento urbano: para quê e para quem? Revista de Direito da Cidade, vol. 4, 2012, no 1. ISSN 2317-7721 p.91- 119 93. Disponível em: www.epublicacoes.uerj.br/index.php/rdc/article/viewFile/9699/7599. Acesso em 02 de abril de 2016.

SANTOS, Milton. Por uma outra globalização: do pensamento único à consciência universal. $9^{a}$ ed. Rio de janeiro: Record, 2002.

A cidade e o urbano como espaço-tempo. Cidade \& História - Modernização das Cidades Brasileiras nos Séculos XIX e XX. UFBA - FAU/MAU. Salvador, 1992: 241-244.

SCHMIDT, Joao P. Público, comunitário e privado: direitos e bem-estar na perspectiva do paradigma comunitarista. Espaço Jurídico Journal of Law, Editora da UNOESC, Joaçaba, v. 16, n. 2, p. 333-360, jul./dez. 2015.

Para entender as políticas públicas: aspectos conceituais e metodológicos. In: REIS, J.R; LEAL, R. G.. (Org.). Direitos sociais e políticas públicas: desafios contemporâneos. Santa Cruz do Sul: Edunisc, 2008, v. 8, p. 2307-2333.

SILVA, Frederico B.; JACCOUD; Luciana; BEGHIN, Nathalie. Políticas sociais no Brasil: participação social, conselhos e parcerias. In: JACCOUD, Luciana et al (org.) Questão social e políticas sociais no Brasil contemporâneo. Brasília: IPEA, 2005.

STROHAECKER, Adriana M. O (des)respeito aos direitos fundamentais à moradia e ao trabalho nos reassentamentos de famílias de baixa renda: considerações teóricas e estudo de caso da Vila Chocolatão. 
Universidade Federal do Rio Grande do Sul, 2011. Trabalho de Conclusão de Curso. Disponível em: http://biblioteca.versila.com/2439851. Acesso em 12/05/2016.

VILLAÇA, Flávio. Espaço intra-urbano no Brasil. São Paulo: Studio Nobel: FAPESP: Lincoln Institute, 2001.

Trabalho enviado em 26 de maio de 2016.

Aceito em 31 de agosto de 2016. 